\title{
Presentism and times as propositions
}

\author{
Luca Banfi $^{1}$ - Daniel Deasy ${ }^{1}$ (D)
}

Accepted: 17 June 2021/Published online: 5 July 2021

(C) The Author(s) 2021

\begin{abstract}
Some Presentists-according to whom everything is present-identify instants of time with propositions of a certain kind. However, the view that times are propositions seems to be at odds with Presentism: if there are times then there are past times, and therefore things that are past; but how could there be things that are past if everything is present? In this paper, we describe the Presentist view that times are propositions (Sect. 2); we set out the argument that Presentism is incompatible with the view that times are propositions (Sect. 3); and then we describe three possible responses to that argument on behalf of Presentists who identify times with propositions (Sect. 4). We argue that each of these responses comes with significant costs. Finally, we describe a fourth possible responseaccording to which times are irreducibly higher-order entities-which appears to avoid the costs of the other three (Sect. 5). We also describe and respond to two objections to the higher-order strategy (Sect. 6).
\end{abstract}

\section{Introduction}

Some Presentists - according to whom everything is present-identify instants of time with propositions of a certain kind. However, the view that times are propositions seems to be at odds with Presentism: if there are times then there are past times, and therefore things that are past; but how could there be things that are past if everything is present? In this paper, we describe the Presentist view that times are propositions (Sect. 2); we set out the argument that Presentism is

\footnotetext{
Daniel Deasy

daniel.deasy@ucd.ie

Luca Banfi

luca.banfi@ucdconnect.ie

1 School of Philosophy, University College Dublin, Dublin, Ireland
} 
incompatible with the view that times are propositions (Sect. 3); and then we describe three possible responses to that argument on behalf of Presentists who identify times with propositions (Sect. 4). We argue that each of these responses comes with significant costs. Finally, we describe a fourth possible responseaccording to which times are irreducibly higher-order entities-which appears to avoid the costs of the other three (Sect. 5). We also describe and respond to two objections to the higher-order strategy (Sect. 6).

\section{Times as propositions}

Presentists in the philosophy of time hold that everything is present, or, equivalently, that there are no merely past or future things: no Joan of Arc, no Battle of Borodino, no colonisation of Mars, no inauguration of the first Martian president. We take this as our official definition of Presentism (with the quantifier read as unrestricted): ${ }^{1}$

PRESENTISM: Everything is present

$\forall x(\operatorname{Present}(x))$

For example, here is Crisp: ${ }^{2}$

Presentism is the claim that it is always the case that, quantifying unrestrictedly, for every $\mathrm{x}, \mathrm{x}$ is present. (Crisp, 2007, 107, fn. 1)

There has been some debate about whether Presentism as defined above expresses a non-trivial thesis, and about exactly what it means for something to be present in the sense of Presentism. ${ }^{3}$ In this paper we side-step those debates. Our interest here is in describing an argument against a certain kind of Presentism, and then assessing some possible responses to that argument.

The kind of Presentism we are interested in combines Presentism as defined above with the view that there are instants of time, where times are identified with instant-propositions. Instant-propositions can be thought of as instantaneous 'snapshots' of the whole of reality: statements that fully describe the totality of what there is and how things are at a moment. More formally, we can define an instant-proposition as a maximal, consistent, sometimes true proposition:

INSTANT-PROPOSITION: For any $p, p$ is an instant-proposition $=_{\text {def }} p$ is maximal, consistent, and sometimes true

To say that a proposition $P$ is maximal is to say that for any $p$, either $P$ entails $p$ or $P$ entails not- $p$; to say that $P$ is consistent is to say that there is no $p$ such that $P$ entails both $p$ and not- $p$; and to say that $P$ is sometimes true is to say that $p$ either

\footnotetext{
1 We address the question of whether the quantifier should in fact be read as restricted in Sect. 4.3 below.

2 See also Markosian (2004, 47).

3 On the former debate see e.g. Lombard (1999), Merricks (1995), Sider (2006), Stoneham (2009), and Tallant (2014). On the latter debate see e.g. Cameron (2016), Deasy (2017), and Tallant (2019).
} 
is true, was true, or will be true. Putting all this together gives us our formal definition of 'instant-proposition' (where ' $I p$ ' means ' $p$ is an instant-proposition'):

$$
\begin{aligned}
& \forall p\left(I p==_{\text {def }} \forall q(\square(p \rightarrow q) \vee \square(p \rightarrow \neg q)) \wedge \neg \exists r \square(p \rightarrow(r \wedge \neg r)) \wedge(\mathrm{P} p \vee p \vee\right. \\
& \mathrm{F} p))^{4}
\end{aligned}
$$

Call the view that there are times and times are instant-propositions 'Times as Propositions', or 'TAP' for short:

TIMES AS PROPOSITIONS (TAP): There are times and times are instantpropositions

We assume that times are ordered by a transitive, asymmetric earlier than relation. Given TAP, Presentists can accept the following definitions of what it is for a time to be present; what it is for one time to be earlier than another; and what it is for something to be the case at a time:

PRESENTNESS (TAP): For any time $t, t$ is present $=_{\mathrm{def}} t^{5}$

$\forall t\left(\operatorname{Present}(t)=_{\mathrm{def}} t\right)$

PRECEDENCE (TAP): For any times $t_{1}$ and $t_{2}, t_{1}$ is earlier than $t_{2}=_{\text {def }}$ whenever $t_{1}$ is present, $t_{2}$ will be present

$\forall t_{1} \forall t_{2}\left(t_{1}<t_{2}=\right.$ def $\left.\mathrm{A}\left(\operatorname{Present}\left(t_{1}\right) \rightarrow \mathrm{F}\left(\operatorname{Present}\left(t_{2}\right)\right)\right)\right)$

TRUTH-AT-A-TIME (TAP): For any $p$ and time $t, p$ is true at time $t={ }_{\text {def }}$ $t$ entails $p$

$\forall p \forall t\left(\right.$ At $\left.t, p={ }_{\text {def }} \square(t \rightarrow p)\right)$

In other words, if times are instant-propositions, then the present time is the true instantaneous 'snapshot' of reality; one time is earlier than another just in case whenever the first 'snapshot' is present, the second will be present; and something is the case at a time just in case it is entailed by the relevant 'snapshot'.6,7

A number of well-known Presentists endorse TAP. For example, here is Markosian:

\footnotetext{
${ }^{4}$ Given that the definition of 'instant-proposition' involves the tense operators ' $P$ ' ('It was the case that') and ' $F$ ' ('It will be the case that'), TAP does not provide the basis for a reductive analysis of the tense operators. Therefore, Presentists who accept TAP must still hold that some tense operators (or more precisely, the properties of propositions that they express) are fundamental. Rasmussen (2012) argues that Presentists who accept TAP can at least provide a reductive analysis of the 'A-properties', that is, the properties of times of being past, being present and being future; see Tallant (2012) for a response.

5 This may seem odd, but remember that given TAP, times are propositions.

${ }^{6}$ Presentists who accept TAP do not have to accept all of these definitions. For example, Crisp (2007) combines Presentism with TAP but holds that the earlier than relation between times is fundamental.

7 Some might worry that TAP is incompatible with certain genuine possibilities, such as that there is sometimes an extended interval without change, or that time is circular. In order to allow for such possibilities, Presentists who accept TAP can posit 'snapshot-events': instantaneous, non-repeatable events whose occurrence distinguishes e.g. the moments that make up some interval during which there is otherwise no change. An example of such an event is the event of its being $n$, where ' $n$ ' names this time.
} 
There is the abstract present time, which is a maximal, consistent proposition. There are many things that are similar to the abstract present time in being maximal, consistent propositions that either will be true, are true, or have been true. Each one is a time. The abstract present time is the only one of all of these abstract times that happens to be true right now. (Markosian, 2004, 33)

And here is Prior:

We can identify an instant with a tensed proposition, namely with the conjunction of everything that would ordinarily be said to be true at that instant; or alternatively, with something that would ordinarily be said to be true at that instant only. We can then interpret being true at an instant as being necessarily or omnitemporally implied by that instant (considered as a proposition), and one instant's being earlier than another as the futurity of the latter being true 'at' the former, i.e. with the former's necessarily or omnitemporally implying the latter will be the case. (Prior, 1968, 138).

Why would a Presentist accept TAP ${ }^{8}$ We will not rehearse the arguments in detail here, but it is clear that Presentists face pressure from a number of directions to posit instants of time. For example, there is pressure from physics: many physical equations include time-variables, including the famous Schrödinger equation (which describes the evolution of the wave function in a quantum-mechanical system) and relativistic equations such as the Hamiltonian formulation of quantum field theories. ${ }^{9}$ There is also pressure from the semantics of tense: the most successful theories of tense in English - and in particular, of tense in embedded clauses - treat tensed sentences as involving either quantification over times (or intervals of time) or direct reference to contextually salient times (or intervals of time). ${ }^{10}$ Finally, and relatedly, there is pressure from ordinary thought and speech: expressions such as 'every time', 'the time that', 'yesterday', 'in 1996' etc. abound in ordinary thought and speech, and seem to indicate direct reference to times or intervals of time ${ }^{11}$.

Why do Presentists who accept the existence of times identify times with instantpropositions? It is plausible that some such Presentists reason as follows: Presentists are committed to the view that everything is present, from which it follows that nothing is at a temporal distance from anything else. Therefore times, whatever they are, do not stand at a temporal distance from anything else. But propositions - and

\footnotetext{
8 The combination of Presentism and TAP is also defended by Bourne (2006) and Crisp (2007). Rasmussen (2012) explores the consequences of the view, but does not endorse it.

${ }^{9}$ Some philosophers and physicists argue that a completed theory of quantum gravity (which seeks to reconcile quantum mechanics with the general theory of relativity) will contain no temporal notions, and therefore that in some sense, fundamental physical reality is 'timeless'; see especially Baron et al.(2019). However, the point here is not that Presentists are under pressure to posit times as fundamental entities. There may be pressure to posit times, even if times are themselves ultimately non-fundamental.

${ }^{10}$ See, for example, Montague (1973), Ogihara (1995), and Partee (1973). For an overview see Fernando (2015).

11 We do not deny that Presentists can try to resist these pressures; for example, by treating 'times' as a useful fiction. We simply note that there are such pressures, and that they provide at least a plausible motivation for the acceptance of TAP.
} 
therefore instant-propositions - are abstract objects, and abstract objects by their nature do not stand at a temporal distance from anything else. Therefore, there is no threat to the truth of Presentism from the identification of times with instantpropositions - in short, TAP is a Presentist-friendly thesis. ${ }^{12}$

Before continuing, we wish to anticipate an objection: that is, that (some, many) Presentists who posit instant-propositions do not identify them with times as per TAP, but merely take them to 'represent' times. ${ }^{13}$ The idea, we assume, is as follows: given an acceptance of instant-propositions, Presentists can provide 'truthmakers' for ordinary 'tenseless' sentences such as 'As of 1066, William is conquering England', which appear to involve direct reference to non-present times or intervals. However, when speaking strictly and literally-for example, in the context of metaphysical theorising - such Presentists assert that there are no times, or that there is exactly one (non-propositional) time. ${ }^{14}$ Therefore they do not (strictly speaking) accept TAP.

Whilst we do not deny that Presentists who posit instant-propositions could take this view, we think the quotations from Markosian (2004) and Prior (1968) above strongly suggest the identification of times with instant-propositions, and therefore an acceptance of TAP (Markosian: 'each one [i.e. instant-proposition] is a time'; Prior: 'we can identify an instant with a tensed proposition'). ${ }^{15}$ As Rasmussen (2015) puts it, we think such Presentists 'take times seriously'. But even if they do not, we think there is value in exploring the consequences of the combination of Presentism with TAP.

Just above, we described an argument for the conclusion that TAP is a Presentistfriendly thesis. In the next section, we describe an argument for the conclusion that TAP is in fact incompatible with Presentism.

\footnotetext{
${ }^{12}$ We do not endorse this argument. However, we do think that there is an attractive way for Presentists to make good on the idea that TAP is a Presentist-friendly thesis: that is, by treating times as irreducibly higher-order entities. See Sect. 5 below.

13 As Rasmussen (2015, 3223) points out, the language of 'ersatz times' (see e.g. Tallant, 2012) encourages this (mis)interpretation: just as a fake diamond is not a diamond, one may naturally infer that an ersatz time is not a time. To prevent confusion, we avoid using the expression 'ersatz time' in this paper.

14 In the former case, 'time' might mean e.g. 'maximal, simultaneous region of spacetime'. Given the common Presentist view that there are no points or regions of spacetime, it would follow that there are no times. In the latter case, 'time' might mean e.g. 'maximal, instantaneous event', or 'true instantproposition'.

15 See also Crisp (2007, 99; our emphasis): 'Let us think of a time as any proposition that...', and Rasmussen (2012, 273; our emphasis): 'I propose the following four theses, each of which an ersatz presentist may endorse. Firstly, times are abstract entities (e.g. maximal propositions) that bear primitive earlier than and later than relations to one another'.
} 


\section{The argument}

There is a simple argument for the conclusion that TAP is incompatible with Presentism, as follows: if TAP is true, then there are at least two times, one of which is earlier than the other. But necessarily, if there are two things one of which is earlier than the other, at least one of them is not present; therefore if TAP is true, something is not present. Call this The Argument: ${ }^{16}$

THE ARGUMENT

(1) If TAP is true then there are at least two times, one of which is earlier than the other

(2) Necessarily, if there are two things one of which is earlier than the other then at least one of them is not present

Therefore:

(c) If TAP is true, something is not present

Premise (1) describes an uncontroversial implication of TAP: given as we assume that times are ordered by an earlier than relation, if there are times then there are at least two times one of which is earlier than the other. Premise (2) makes a substantial but, we think, very plausible general claim about the earlier than relation: namely, that it must be that if two things stand in it, at least one of them is not present; or, equivalently, that it couldn't be that two things are both present and yet one is earlier than the other. Call this principle Earlier:

EARLIER: Necessarily, if there are two things one of which is earlier than the other then at least one of them is not present

$\square \forall x \forall y(x<y \rightarrow(\neg \operatorname{Present}(x) \vee \neg \operatorname{Present}(y)))$

Finally, the conclusion (c) of The Argument follows straightforwardly from (1) and (2). And given (c), TAP is incompatible with Presentism.

\section{Three responses to the argument}

In this section, we describe three possible responses to The Argument on behalf of Presentists who accept TAP. They are: to distinguish two senses of the predicate 'is present'; to distinguish two senses of the predicate 'is earlier than'; to restrict Presentism to the concrete. As we shall see, each of these responses comes with significant costs.

\footnotetext{
${ }^{16}$ The Argument is not without precedent: as we shall see below, Crisp (2007) raises a version of it against his own view. Tallant (2012, 674-5) also raises a version of it against Rasmussen's (2012) claim that given TAP, Presentists can provide a reductive analysis of the 'A-properties'.
} 


\subsection{Two senses of 'is present'}

Crisp (2007) defends the combination of Presentism with TAP. ${ }^{17}$ And Crisp is clearly aware of the apparent tension between Presentism and TAP; he writes:

I propose that abstract times are related by the earlier than relation. But isn't this hypothesis at odds with presentism? According to the presentist, everything is present. But then nothing-not even an abstract time-can be earlier than the present time; else not everything is present. (Crisp, 2007, 102).

His (ibid, 102-3) response is to distinguish two senses of the predicate 'is present':

Everything is present, says the presentist; that is, everything is present ${ }_{1}$. But if she believes in abstract times, she'll think there's another sort of presentnesspresentness $_{2}$ let us say-such that only one among the infinity of times-the present time-has this property. What is this presentness ${ }_{2}$ ? I'll suggest below that a time is present $_{2}$ iff it is the true time, the time which has the property being true. (Crisp, 2007, 103)

In terms of The Argument, Crisp's response amounts to a rejection of premise (2), i.e. of Earlier. The idea is that having distinguished between the property of presentness $_{1}$, which according to Presentists is possessed by everything (quantifying unrestrictedly), and the property of presentness ${ }_{2}$, which uniquely applies to the true instant-proposition, the Presentist can distinguish two interpretations of Earlier:

EARLIER $_{1}$ : Necessarily, if there are two things one of which is earlier than the other then at least one of them is not present 1

EARLIER $_{2}$ : Necessarily, if there are two things one of which is earlier than the other then at least one of them is not present 2

Now suppose that the instances of the predicate 'is present' in The Argument are interpreted as expressing presentness $_{1}$. In that case, premise (2) of The Argument is equivalent to Earlier ${ }_{1}$. But according to Crisp, Earlier ${ }_{1}$ is false: given that everything (quantifying unrestrictedly) is present $_{1}$, instant-propositions provide a counterexample. On the other hand, suppose that the instances of the predicate 'is present' in The Argument are interpreted as expressing presentness $s_{2}$. In that case, premise (2) of The Argument is equivalent to Earlier $_{2}$. And given that necessarily, presentness 2 is uniquely possessed by the true instant-proposition and no instant-proposition is earlier than itself, Earlier 2 is true. It follows that if TAP is true, something (i.e. some instant-proposition) is not present ${ }_{2}$. But of course, that is compatible with the view that everything (quantifying unrestrictedly) is present $_{1}$, and therefore compatible with Presentism.

We agree with Crisp that Presentists who accept TAP should take care to distinguish the property of being present $_{1}$ (in terms of which Presentism is stated) from the property of being present 2 (which is equivalent to the property of being the

\footnotetext{
17 Although note that for Crisp, the earlier than relation between times is fundamental-more on this below in Sect. 4.2.
} 
true instant-proposition). However, Earlier seems plausible to us on both interpretations. In particular, however one defines the property of presentness ${ }_{1}$, it is very hard to believe that there could be two things-even abstract objects-both of which are present ${ }_{1}$ and one of which is earlier than the other. Therefore, we count it as a cost of Crisp's response to The Argument that it implies the falsehood of Earlier $_{1}$. It would be nice to find a response to The Argument that allowed Presentists to avoid this cost.

\subsection{Two senses of 'is earlier than'}

We have seen that one way for Presentists who accept TAP to respond to The Argument is to distinguish two senses of the predicate 'is present'-as expressing the property in terms of which Presentism is stated, and as expressing the property of being the true instant-proposition-and then to reject Earlier ${ }_{1}$. A different strategy is to distinguish two senses of the predicate 'is earlier than': that is, as expressing a fundamental relation and a non-fundamental relation. ${ }^{18}$ Given such a distinction, there are at least two ways of interpreting Earlier ${ }_{1}:{ }^{19}$

EARLIER $_{3}$ : Necessarily, if there are two things one of which is fundamentally earlier than the other then at least one of them is not present ${ }_{1}$

EARLIER $_{4}$ : Necessarily, if there are two things one of which is nonfundamentally earlier than the other then at least one of them is not present ${ }_{1}$

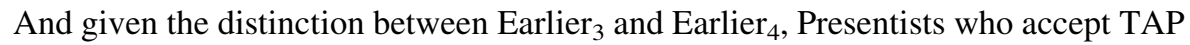
can argue that Earlier ${ }_{1}$ is only plausible when it is interpreted as equivalent to Earlier $_{3}$ (i.e. as concerning a fundamental earlier than relation between times); and on their view, nothing is fundamentally earlier than anything else, because the earlier than relation between times can be reductively analysed as follows (see Sect. 2 above):

PRECEDENCE (TAP): For any times $t_{1}$ and $t_{2}, t_{1}$ is earlier than $t_{2}=_{\text {def }}$ whenever $t_{1}$ is present, $t_{2}$ will be present $\forall t_{1} \forall t_{2}\left(t_{1}<t_{2}={ }_{\text {def }} \mathrm{A}\left(\operatorname{Present}\left(t_{1}\right) \rightarrow \mathrm{F}\left(\operatorname{Present}\left(t_{2}\right)\right)\right)\right){ }^{20}$

It follows that this response is not available to Presentists such as Crisp (2007, 102) according to whom the earlier than relation between times is fundamental. However, we cannot see any good reason why Presentists who accept TAP should

\footnotetext{
18 By 'fundamental (monadic or polyadic) property' here and throughout we mean a property that 'carves reality at the joints' or is 'perfectly natural' in the sense of Lewis (1983).

${ }^{19}$ We focus here on interpretations of Earlier 1 , as we assume that no Presentist who accepts TAP will contemplate rejecting Earlier 2 .

${ }^{20}$ What about truths concerning temporal relations between non-times, such as 'The storm was earlier than the flood'? Assuming that the storm and the flood do not temporally overlap, this sentence could be interpreted as follows: for any times $t_{1}$ and $t_{2}$, if $t_{1}$ entails that the storm is occurring and $t_{2}$ entails that the flood is occurring, then whenever $t_{1}$ is present $t_{2}$ will be present. Truths concerning temporal relations between temporally overlapping events will naturally require a more complicated analysis; we do not pursue that further here.
} 
not accept the above analysis. Therefore, we do not count it as a significant cost of this response that it is not available to such Presentists.

The question is whether the current response is an improvement over that described in Sect. 4.1 above. We do not think it is, because-like the previous response-it involves the implausible rejection of a version of Earlier. In particular, as we saw above, the current response relies on a rejection of Earlier ${ }_{4}$, and therefore requires one to accept that there could be two things, both of which are present ${ }_{1}$ and one of which is non-fundamentally earlier than the other.

One might fail to see the cost of accepting this claim on the basis of the view that if some $x$ is non-fundamentally earlier than some $y$, then $x$ is not really earlier than $y$. But we think that would be a mistake: that a property or relation is nonfundamental does not make it any less real; reductive analysis is not elimination. Racism would be morally wrong even if it were possible to provide a reductive analysis of the property of being morally wrong, and some actions would be intentional even if were possible to provide a reductive analysis of the property of being an intentional action. More generally, the fact that a property $F$ is nonfundamental does not mean that nothing is really $F$. Therefore, we count it as a cost

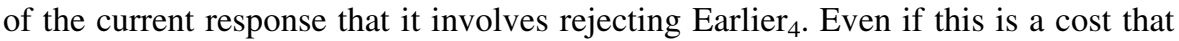
Presentists who accept TAP might be willing to pay to avoid The Argument, it remains the case that it would be nice to find a response to The Argument that allowed Presentists to avoid this cost.

\subsection{Restricting Presentism to the concrete}

So far, we have examined responses to The Argument which involve disambiguating certain expressions which appear in the premises of that argument. But it may have occurred to some readers that there is a much simpler response available to Presentists who accept TAP: that is, to restrict Presentism to the concrete. In that case, Presentists can accept the conclusion (c) of The Argument as a claim about presentness $_{1}$, but deny that TAP is incompatible with Presentism on the grounds that if TAP is true, some non-concrete things are non-present ${ }_{1}$, and Presentism is the view that everything concrete is present $_{1}$ :

PRESENTISM (RESTRICTED): Everything concrete is present ${ }_{1}$

$\forall x\left(\operatorname{Concrete}(x) \rightarrow \operatorname{Present}_{1}(x)\right)$

According to such Presentists, instant-propositions are non-present ${ }_{1}$, but given that instant-propositions are abstract and therefore non-concrete, their existence is compatible with Presentism.

This response involves two substantial claims: that instant-propositions are nonconcrete, and that Presentism should be interpreted as restricted to the concrete. In order to assess these claims, we need to have some grasp of the meaning of the predicate 'is concrete'. We don't suppose it is possible to provide a strict definition of concreteness. ${ }^{21}$ For instance, a tempting thought is that for something to be

21 See e.g. Williamson (2013, chapter 1$)$. 
concrete is for it to occupy space. However, there may be things that we would wish to count as concrete but that we would be reluctant to count as occupying space, such as smiles and the electromagnetic field. Perhaps the best way to grasp the notion of concreteness is via examples: for instance, galaxies, mountains, and atoms are certainly concrete, but numbers and sets (if there are such objects) are nonconcrete.

The claim that instant-propositions are non-concrete seems plausible on the assumption that propositions are abstract objects, and if something is abstract then it is necessarily non-concrete. However, we note here the sheer strangeness of the view that propositions are abstract objects. For example, if propositions are abstract objects, to believe something is to bear a certain cognitive relation to a necessarily non-concrete object. But how could a concrete thing like you or I ever come to stand in such a relation to such an object? And how could such an object bear the representational properties it is supposed to bear? ${ }^{22}$ We do not doubt that there are stories that can be told. ${ }^{23}$ But it would be nice if Presentists could somehow gain the advantages of TAP without having to accept that propositions are abstract objects.

The claim that Presentism should be restricted to the concrete seems, on the face of it, to represent a cost of the current strategy. For one thing, as we saw above, it seems unlikely that concreteness can be strictly defined; given the familiar worries about providing a strict definition of the notion of presentness $s_{1}$ in terms of which Presentism is stated, ${ }^{24}$ restricting Presentism to the concrete may be thought to make the thesis doubly obscure. Second, it is natural to think that a significant part of the interest of metaphysical theses such as Presentism lies in their universality. This universality is clearly lost if Presentism is restricted to the concrete.

On the other hand, defenders of the current strategy may argue that there are independent reasons to expect Presentism to be restricted to the concrete. As Tallant and Ingram (2018, Sect. 2) write (where 'PA' refers to the thesis that always, only present things exist):

First, strictly speaking, on this characterization [i.e. as PA], presentism is a thesis that denies the existence of atemporal or timeless entities, that is, entities that aren't present (but aren't past or future either). This appears to rule out the existence of abstract entities... And this may be a step too far for some presentists. Hence, we might be pressed to modify PA and restrict it to concrete objects.

In other words, on the assumption that things like numbers, properties and propositions are abstract objects and abstract objects are 'atemporal' or 'timeless' and hence necessarily non-present ${ }_{1}$ - Presentism as an unrestricted thesis implies that there are no numbers, properties or propositions. Given that there are such

\footnotetext{
22 See Jones (2019) for an argument that propositions conceived as objects (whether they are abstract or not) cannot play the role they are supposed to play in characterising propositional attitudes such as belief.

23 See e.g. Merricks (2015).

${ }^{24}$ See e.g. Cameron (2016), Deasy (2017), and Tallant (2019).
} 
things (the argument goes), we should expect Presentism to be restricted to the concrete.

However, the view that propositions are abstract objects and abstract objects are atemporal does not sit well with TAP. If propositions are abstract objects and abstract objects are atemporal, then given TAP, some times are atemporal. But how could times be atemporal? Even if we specify that being atemporal means e.g. being necessarily neither past $_{1}$, present $_{1}$, nor future ${ }_{1}$, there is still something very strange about the claim that times are atemporal (or even worse: that times are timeless). It follows that Presentists who accept TAP do not seem to be in a good position to appeal to the argument from atemporal abstracta against the unrestricted interpretation of Presentism. ${ }^{25}$

\section{The higher-order strategy}

In the previous section we described three possible responses to The Argument on behalf of Presentists who accept TAP. We argued that each of those responses comes with significant costs. In this section, we describe a fourth response to The Argument which avoids those costs: to identify times with irreducibly higher-order entities.

Readers will notice that both our formal and informal definitions of instantproposition' in Sect. 2 above are expressed using higher-order quantification into sentence position-i.e. using quantifiers that bind variables of the semantic type of complete declarative sentences-rather than first-order 'objectual' quantification over objects such as propositions or sentences. The difference between first-order and higher-order quantification can be illustrated by the following pairs of sentences:

(3) $\exists x \exists y($ Property $(y) \wedge \mathrm{S}($ Instantiates $(x, y)) \wedge \mathrm{S}(\neg$ Instantiates $(x, y)))$

(3*) $\exists x \exists F(\mathrm{~S} F x \wedge \mathrm{S} \neg F x)$

(4) $\exists x(\operatorname{Proposition}(x) \wedge \mathrm{S}(\operatorname{True}(x)) \wedge \mathrm{S}(\neg \operatorname{True}(x)))$

(4*) $\exists p(\mathrm{~S} p \wedge \mathrm{S} \neg p)$

Sentence (3) is intended to be read as saying that there is a certain object-a property - that something sometimes instantiates and sometimes does not instantiate. And sentence $\left(3^{*}\right)$ can be read in much the same way. However, there is an important difference in the way that (3) and $(3 *)$ are expressed: whereas the quantifiers in (3) ( $~ \exists x$ ', ' $\left.\exists y^{\prime}\right)$ are the familiar quantifiers of first-order predicate logic, $\left(3^{*}\right)$ also contains the second-order quantifier ' $\exists F$ ', which quantifies into predicate rather than nominal position. ${ }^{26}$ Similarly, whilst sentences (4) and (4*) can both be read as saying that some proposition is sometimes true and sometimes false, there is an important difference in how they are expressed: whereas the quantifier in (4) is a

\footnotetext{
25 The alternative, as Tallant \& Ingram point out, is to simply accept that given Presentism, abstract objects if there are such are present ${ }_{1}$ (and therefore in some sense 'in time').

26 Second-order logic was first developed by Frege (1879). See also Bostock (2004).
} 
familiar first-order quantifier, the quantifier in $\left(4^{*}\right)\left({ }^{\prime} \exists p^{\prime}\right)$ is a higher-order quantifier into sentence position.

Considering the pairs of sentences above, a natural question arises: how should we interpret the higher-order quantifiers ' $\exists F$ ' and ' $\exists p$ ' that appear in sentences $\left(3^{*}\right)$ and $\left(4^{*}\right)$ ? In order to answer this question, it is natural to start by looking at the formal semantics of the higher-order quantifiers. As with the semantics of the firstorder quantifiers, the notions of a model and a variable assignment first need to be defined. A model $\mathcal{M}$ is defined as usual as an ordered pair $\mathcal{D}, \mathcal{J}$, where $\mathcal{D}$ is a nonempty set ('the domain') and $\mathcal{J}$ is a function that assigns to each constant a member of the domain, and to each $n$-place predicate letter an $n$-ary relation over $\mathcal{D}$. However, as distinct from individual variables (' $x$ ', ' $y$ ', etc.), predicate variables (' $F$ ', ' $G$ ', etc.) and sentence variables (' $p$ ', ' $s$ ', etc.) are not assigned members of the domain. Suppose we think of sentence variables as a species of predicate variables, such that sentence variables are simply $n$-place predicate variables where $n=0$ (i.e. variables that do not require any individual to form a sentence). Then, a variable assignment $\mathrm{A}$ over a model $\mathcal{M}$ of predicate and sentence variables is a function that assigns a set of $n$-tuples over $\mathcal{D}$ to every predicate variable (where $n>0$ ) and to every sentence variable (where $n=0$ ).

Given a model $\mathcal{M}$, a variable assignment $\mathrm{A}$ over $\mathcal{M}$, and any higher-order (sentence or predicate) variable $X$, the higher-order quantifiers can be characterised as follows:

HO- $\forall: \forall X \varphi$ is true under $\mathrm{A}$ if and only if every $R$ is such that $\varphi$ is true under $\underline{\mathrm{A}}[X / R]$, which is the same as $\underline{\mathrm{A}}$ except at most that it assigns the set of $n$-tuples $\bar{R}$ over $\mathcal{D}$ to $X$

HO- $\exists$ : $\exists X \varphi$ is true under $\underline{\mathrm{A}}$ if and only if some $R$ is such that $\varphi$ is true under $\underline{\mathrm{A}}[\mathrm{X} / R]$, which is the same as $\underline{\mathrm{A}}$ except at most that it assigns the set of $n$ tuples $R$ over $\mathcal{D}$ to $X$

What these definitions show us is that the semantic clauses for the higher-order quantifiers interpret higher-order quantification in terms of first-order quantification over sets ('every $R$ ' in $\mathrm{HO}-\forall$ and 'some $R$ ' in $\mathrm{HO}-\exists$ ).

Does that mean we must interpret higher-order quantification in terms of firstorder quantification over sets? Those familiar with the semantics of e.g. tense and modal logic — on which the tense operators (such as ' $\mathrm{S}$ ', 'It is sometimes the case that') and modal operators (such as ' $\diamond$ ', 'It is possible that') are interpreted in terms of first-order quantification over times and worlds respectively-will be familiar with the idea that certain expressions (or more precisely, that which they express) can be taken as fundamental even when their semantic clauses seem to interpret them in other terms. For instance, most Presentists-including those who accept TAP - hold that some tense operators express fundamental properties, despite the tense-logical interpretation of the tense operators as quantifiers over times. ${ }^{27}$ So, the interpretation of the higher-order quantifiers in terms of first-order quantification over sets is certainly not forced by the semantics of higher-order logic.

$\overline{27}$ We assume that tense operators express properties of propositions, such as being past or being future. 
Even so, many philosophers have defended interpretations of the higher-order quantifiers in other terms. As we have seen, one option is to interpret the higherorder quantifiers in terms of first-order quantification over sets. ${ }^{28}$ Another is to interpret them in terms of first-order quantification over abstract objects such as properties and propositions. Another well-known strategy due to Boolos (1985) is to interpret higher-order quantification in terms of plural quantification, e.g. in terms of quantifiers such as ' $\forall x x$ ' and ' $\exists x x$ ', read as 'For any things' and 'For some things' respectively. And finally, on at least some versions of the 'substitutional' interpretation of the quantifiers, higher-order quantifiers are interpreted in terms of first-order quantification over linguistic entities of the relevant type (i.e. predicates, sentences, etc.). ${ }^{29}$

We are not in a position to assess all of the above strategies here. Rather, our interest is in exploring the consequences of a different approach to higher-order quantification: one that takes higher-order quantification as metaphysically fundamental, and therefore irreducible. Call the former thesis Higher-Order Primitivism, or 'HOP' for short:

HIGHER-ORDER PRIMITIVISM (HOP): Higher-order quantification is fundamental

HOP has been defended by (among others) Bostock (2004); Jones (2018, 2019); Prior (1971, chapter 2); Rayo and Yablo (2001); and Williamson (2003, 2013). For instance, Jones $(2019,12)$ expresses a commitment to the view that propositions are irreducibly higher-order entities ('entities of type $t$ '):

Finally, if propositions are not objects, there is no debate to be had about what kind of object they are. Propositions aren't sets, or $n$-tuples, or any other kind of object. Rather, propositions are familiar entities of type $t$ that all theorists implicitly recognise, for example: Tibbles is hungry, the sun is shining.

One immediate problem for defenders of HOP is that it is hard to express higherorder quantification in ordinary language; for example, as we saw above, it is natural to read sentences $\left(3^{*}\right)$ and $\left(4^{*}\right)$ as involving first-order quantification over properties and propositions respectively. As Prior $(1971,37)$ notes, 'forms like 'For some $p, p$ ' are not idiomatic English, perhaps not even idiomatic Indo-European'. Therefore, in the rest of what follows, quantification over objects such as properties and propositions should be interpreted as higher-order quantification, unless otherwise specified.

We are now in a position to describe our final response to The Argument on behalf of Presentists who accept TAP. Suppose Presentists who accept TAP also

\footnotetext{
${ }^{28}$ See especially Quine (1986, 66-8).

29 See especially Marcus $(1961,1962)$ on substitutional quantification. Note, however, that Marcus (like many of those who defend substitutional quantification) does not treat substitutional quantification as equivalent to first-order quantification over linguistic entities (of the relevant type). Rather, sentences involving first-order quantification over linguistic entities (of the relevant type) are regarded as merely providing truth-conditions for the relevant sentences involving substitutional quantification. See Van Inwagen (1981) for an expression of puzzlement concerning the nature of this relationship.
} 
accept HOP. In that case, they can distinguish two different versions of TAP, as follows:

TIMES AS PROPOSITIONS (FIRST-ORDER): There are (quantifying at the first-order) times, and times are instant-propositions

TIMES AS PROPOSITIONS (HIGHER-ORDER): There are (quantifying at a higher-order) times, and times are instant-propositions

Call these theses 'FOTAP' and 'HOTAP' respectively. FOTAP is the thesis that times are objects, and those objects are instant-propositions. HOTAP is the view that times are higher-order entities, and those higher-order entities are instantpropositions. Given as we saw above in Sect. 2 that instant-propositions can be defined in terms of quantification into sentence position, Presentists who accept HOP can also accept HOTAP; that is, they can hold that times are irreducibly higher-order entities, and those irreducibly higher-order entities are instantpropositions. Moreover, they can reject FOTAP; that is, they can hold that there are no such objects as times. For instance, Prior (1968) explicitly rejects FOTAP:

Instants are not genuine individuals [...] If we prefer to handle instantvariables, for example, or person-variables, as subjects of predicates, then we may be taken to believe in the existence of instants, or of persons. If, on the other hand, we prefer to treat either of these as propositional variables, i.e. as arguments of truth-functions and of modal functions, then we may be taken as not believing in the existence of instants, etc. (they don't exist; rather, they are or are not the case). (Prior, 1968, 142)

Such Presentists can then distinguish two different interpretations of The Argument. The first version concerns FOTAP, and utilises first-order quantification:

(5) If FOTAP is true then there are (quantifying at the first-order) at least two times, one of which is earlier than the other ${ }^{30}$

(6) Necessarily, if there are (quantifying at the first-order) two things one of which is earlier than the other then at least one of them is not present ${ }^{31}$

Therefore.

(c) If FOTAP is true, something (quantifying at the first-order) is not present 1 (from (5) and (6))

It follows from this version of The Argument that FOTAP is incompatible with Presentism, according to which everything (quantifying at the first-order) is present $_{1}$. However, according to the current response, Presentists should reject FOTAP; therefore, they have nothing to fear from this version of The Argument.

\footnotetext{
30 The earlier than relation can be interpreted as expressing either a fundamental or a non-fundamental relation here.

31 As above, we focus on the version of The Argument that appeals to Earlier $_{1}$, as that is the version of the principle that e.g. Crisp (2007) rejects.
} 
The second version of The Argument concerns HOTAP, and utilises higher-order quantification:

(7) If HOTAP is true then there are (quantifying at a higher-order) at least two times, one of which is earlier than the other

(8) Necessarily, if there are (quantifying at a higher-order) two things one of which is earlier than the other then at least one of them is not present ${ }_{1}{ }^{32}$

Therefore.

(c) If HOTAP is true, something (quantifying at a higher-order) is not present 1 (from (7) and (8))

According to the conclusion of this version of The Argument, HOTAP implies that something (quantifying at a higher-order) is not present ${ }_{1}$. And according to the current response, Presentists should accept HOTAP. However, the claim that something (quantifying at a higher-order) is not present $_{1}$ is compatible with Presentism, according to which every object-i.e. everything (quantifying at the first-order) - is present ${ }_{1}$. Therefore, Presentists who accept HOTAP can accept the premises of this version of The Argument.

The current response avoids the costs of the responses to The Argument described in the previous section:

First, unlike Crisp's (2007) response (Sect. 4.1), the current response does not force Presentists to reject the plausible principle Earlier ${ }_{1}$, according to which necessarily, if there are two things one of which is earlier than the other then at least one of them is not present $_{1}$ (where presentness $_{1}$ is the property which according to the definition of Presentism is possessed by everything).

Second, unlike the response described in Sect. 4.2, the current response does not force Presentists to reject the plausible principle Earlier 4 , according to which necessarily, if there are two things one of which is non-fundamentally earlier than the other then at least one of them is not present ${ }_{1}$.

Third, unlike the response described in Sect. 4.3, the current response does not force Presentists to interpret the (first-order) 'universal' quantifier in the statement of Presentism as restricted to concrete objects. Moreover, the current response allows Presentists to gain the advantages of identifying times with instantpropositions without having to accept the strange view that propositions are abstract objects. $^{33}$

We think these are significant advantages of the higher-order strategy. However, we can also imagine Presentists who accept TAP raising objections to the higherorder strategy. In the next and final section, we consider two of these.

\footnotetext{
32 Some might worry that this sentence is ill-formed, on the grounds that the property of presentness ${ }_{1}$ in terms of which Presentism is stated cannot be meaningfully applied to higher-order entities. If it cannot, then we can simply assume that in the context of this version of The Argument, 'present ${ }_{1}$ ' expresses the relevant higher-order analogue of presentness $_{1}$; in other words, the property that every proposition has if the relevant higher-order analogue of Presentism is true.

33 See Jones (2019) on the advantages of an irreducibly higher-order approach to propositions.
} 


\section{Objections and replies}

The first objection is straightforward: Presentists who accept HOTAP, as recommended by the higher-order strategy, should also accept the following higher-order analogue of their view:

PROPOSITIONAL PRESENTISM: Every proposition is present $_{1}{ }^{34}$ $\forall p\left(\operatorname{Present}_{l}(p)\right)$

But Propositional Presentism is incompatible with HOTAP given (7) and (8) above. In short, Presentists who accept HOTAP are back to square one vis-à-vis The Argument.

The question is whether Presentists who accept HOTAP should also accept Propositional Presentism. This is a difficult question to assess; what would it mean to say that every proposition is present ${ }_{1}$ ? It cannot mean that every proposition is either temporarily or permanently true, since given HOTAP, past and future times are exactly (temporarily) false propositions. Nor can it mean that every proposition is either temporarily true or temporarily false, since given HOTAP, it is permanently true that e.g. at $t$, there are dinosaurs (for some specific $t$ ). More generally, Propositional Presentism does not seem to express a distinctively 'Presentist' position regarding the nature or existence of propositions, in the way that (first-order) Presentism is supposed to express a distinctive position regarding the nature or existence of objects. And a similar point applies to the analogous higher-order thesis of Property Presentism, the view that every property is present 1 $\left(\forall F\left(\right.\right.$ Present $\left._{l}(F)\right)$.

The second objection to the higher-order strategy concerns HOP, the view that higher-order quantification is fundamental. The objection is as follows: given that natural languages do not seem to contain higher-order quantification, and given as we saw above that the higher-order quantifiers are semantically defined in terms of first-order quantification over sets, how can we ever come to understand higherorder quantification as distinct from the first-order quantification? The objection says that we cannot: perhaps we can convince ourselves with sufficient practice that we really do understand higher-order quantification as distinct from first-order quantification, but really our understanding is always 'grounded in' or 'based on' our understanding of the first-order quantifiers, which we gain through natural languages such as English. Call this view Higher-Order Scepticism:

HIGHER-ORDER SCEPTICISM: Higher-order quantification must be understood in terms of first-order quantification (over e.g. sets, propositions etc.)

Higher-order Sceptics reason that, since higher-order quantification must be understood in terms of first-order quantification, higher-order quantification cannot be taken as fundamental.

\footnotetext{
34 As mentioned above, if 'present, ${ }_{1}$ ' expresses a property that cannot be applied to higher-order entities, then assume it expresses here the relevant higher-order analogue of presentness ${ }_{1}$.
} 
It may not be possible for defenders of HOP to convince committed Higher-order Sceptics of the possibility of understanding higher-order quantification as distinct from first-order quantification; the sceptic is always in a position to deny that they have gained the relevant understanding. However, those who embrace irreducibly higher-order quantification will naturally argue that it is possible to understand higher-order quantification as distinct from first-order quantification. For one thing, they may point out that, contrary to what Higher-order Sceptics claim, we do utilise higher-order quantification in natural languages, such as in the sentences:

(9) Jane is everything we wanted her to be $\mathrm{e}^{35}$

(10) Jane and John think the same thing

(9) seems to involve quantification into predicate position, and (10) quantification into sentence position. Of course, Higher-order Sceptics may argue that (9) and (10) can be understood in first-order terms-for example, (9) can be understood as equivalent to the sentence 'Every property possessed by Jane is a property we wanted her to possess'. But that it is possible to propose adequate first-order translations of (9) and (10) is not what was at issue-what was at issue is the Higher-order Sceptic's claim that natural languages do not contain higher-order quantification. Sentences such as (9) and (10) above show that that claim is false.

Second, those who accept HOP may argue that even Higher-order Sceptics must admit that some languages contain expressions that are meaningful but nevertheless cannot be adequately translated into other languages. Such expressions can only be fully understood by learning the relevant languages (or a relevant portion thereof). So it goes for higher-order languages, according to those who accept HOP. For instance, given HOP, there is no adequate natural language translation of the sentence 'For some $p, p$ or not- $p$ '-in particular, it is not equivalent to any sentence involving first-order quantification-but that does not mean that the sentence is not meaningful. Rather, it means that in order to understand the sentence, one must learn the relevant higher-order language (or a relevant portion thereof). In short, it means that higher-order quantification must by learned by immersion and not translation. For instance, here is Williamson (2003):

Perhaps no reading in a natural language of quantification into predicate position is wholly satisfactory. If so, that does not show that something is wrong with quantification into predicate position, for it may reflect an expressive inadequacy in natural languages. We may have to learn secondorder languages by the direct method, not by translating them into a language with which we are already familiar. (Williamson, 2003, 459)

Whether this is enough to convince Higher-order Sceptics is a question we leave to them.

35 This example is due to Higginbotham (1998). 
Acknowledgements The authors are grateful to Nicholas K Jones and Lee Walters for helpful comments on earlier drafts of this paper, as well as to audiences from the Universities of Southampton and Tübingen. Luca would like to thank the Irish Research Council for supporting his research for this paper (grant ID: GOIPG/2018/94).

Funding Open Access funding provided by the IReL Consortium.

Open Access This article is licensed under a Creative Commons Attribution 4.0 International License, which permits use, sharing, adaptation, distribution and reproduction in any medium or format, as long as you give appropriate credit to the original author(s) and the source, provide a link to the Creative Commons licence, and indicate if changes were made. The images or other third party material in this article are included in the article's Creative Commons licence, unless indicated otherwise in a credit line to the material. If material is not included in the article's Creative Commons licence and your intended use is not permitted by statutory regulation or exceeds the permitted use, you will need to obtain permission directly from the copyright holder. To view a copy of this licence, visit http:// creativecommons.org/licenses/by/4.0/.

\section{References}

Baron, S., Miller, K., \& Tallant, J. (2019). Temporal fictionalism for a timeless world. Philosophy and Phenomenological Research. https://doi.org/10.1111/phpr.12637

Boolos, G. (1985). Nominalist platonism. The Philosophical Review, 94, 327-344.

Bostock, D. (2004). On motivating higher-order logic. In Smiley TJT. Baldwin (Ed.), Studies in the philosophy of logic and knowledge. Oxford University Press.

Bourne, C. (2006). A future for presentism. Oxford University Press.

Cameron, R. (2016). On characterizing the presentism/eternalism and actualism/possibilism debates. Analytic Philosophy, 57, 110-140.

Crisp, T. (2007). Presentism and the grounding objection. Nô̂s, 41, 90-109.

Deasy, D. (2017). What is presentism? Nô̂s, 51, 378-397.

Fernando, T. (2015). The semantics of tense and aspect. In S. C. F. Lappin (Ed.), The handbook of contemporary semantic theory. Wiley Blackwell.

Frege, G. (1879). Begriffsschrift, eine der arithmetischen nachgebildete Formelsprache des reinen Denkens, Louis Nebert; translated as Concept Script, a formal language of pure thought modelled upon that of arithmetic, by S. Bauer-Mengelberg in J. van Heijenoort (ed.) (1967) From frege to gödel: A source book in mathematical logic, Harvard University Press. pp. 1879-1931.

Higginbotham, J. (1998). On higher-order logic and natural language. Proceedings of the British Academy, 95, 1-27.

Jones, N. K. (2018). Nominalist realism. Nô̂s, 52, 808-835.

Jones, N. K. (2019). Propositions and cognitive relations. Proceedings of the Aristotelian Society, 119, $157-178$.

Lewis, D. (1983). New work for a theory of universals. Australasian Journal of Philosophy, 61, 343-377.

Lombard, L. (1999). On the alleged incompatibility of presentism and temporal parts. Philosophia, 27, 253-260.

Marcus, R. (1961). Modalities: Philosophical essays. NewYork: Oxford University Press.

Marcus, R. (1962). Interpreting quantification. Inquiry, 5, 252-259.

Markosian, N. (2004). In defence of presentism. In D. Zimmerman (Ed.), Oxford studies in metaphysics. (Vol. 1). NewYork: Oxford University Press.

Merricks, T. (1995). On the incompatibility of enduring and perduring entities. Mind, 104, 521-531.

Merricks, T. (2015). Propositions. Oxford University Press.

Montague, R. (1973). The proper treatment of quantification in ordinary English. In P.Suppes, J. Moravcsik, J. Hintikka (eds.) Approaches to natural language (pp.221-242), Dordrecht.

Ogihara. (1995). The semantics of tense in embedded clauses. Linguistic Inquiry, 26, 663-679. 
Partee, B. (1973). Some structural analogies between tenses and pronouns in English. Journal of Philosophy, 70, 601-609.

Prior, A. (1968). Papers on time and tense. Oxford University Press.

Prior, A. (1971). Objects of thought. Oxford University Press.

Quine, W. V. O. (1986). Philosophy of logic. Harvard University Press.

Rasmussen, J. (2012). Presentists may say goodbye to A-properties. Analysis, 72, 270-276.

Rasmussen, J. (2015). Tenseless times. Philosophical Studies, 172, 3221-3227.

Rayo, A., \& Yablo, S. (2001). Nominalism through de-nominalization. Nô̂s, 35, 74-92.

Sider, T. (2006). Quantifiers and temporal ontology. Mind, 115, 75-97.

Stoneham, T. (2009). Time and truth: The presentism-eternalism debate. Philosophy, 84, 201-218.

Tallant, J. (2012). (Existence) presentism and the a-theory. Analysis, 72, 673-681.

Tallant, J. (2014). Defining existence presentism. Erkenntnis, 79, 479-501.

Tallant, J. (2019). Presentism remains. Erkenntnis, 84, 409-435.

Tallant, J. \& D. Ingram (2018). In: E. Presentism. Zalta (ed.) The stanford encyclopedia of philosophy (Spring 2018 Edition) https://plato.stanford.edu/archives/spr2018/entries/presentism/.

Van Inwagen, P. (1981). Why I don't understand substitutional quantification. Philosophical Studies, 39, 281-285.

Williamson, T. (2003). Everything. Philosophical Perspectives, 17, 415-465.

Williamson, T. (2013). Modal logic as metaphysics. Oxford University Press.

Publisher's Note Springer Nature remains neutral with regard to jurisdictional claims in published maps and institutional affiliations. 